\title{
Spinal Cord-Transected Mice Learn to Step in Response to Quipazine Treatment and Robotic Training
}

\author{
Andy J. Fong, ${ }^{3,5}$ Lance L. Cai, ${ }^{5}$ Chad K. Otoshi, ${ }^{2}$ David J. Reinkensmeyer, ${ }^{7,8}$ Joel W. Burdick, ${ }^{5,6}$ Roland R. Roy, ${ }^{4}$ and \\ V. Reggie Edgerton ${ }^{1,4}$ \\ Departments of ${ }^{1}$ Physiological Science and ${ }^{2}$ Neurobiology, ${ }^{3}$ Biomedical Engineering Interdepartmental Program, and ${ }^{4}$ Brain Research Institute, University \\ of California, Los Angeles, Los Angeles, California 90095, Division of Engineering, ${ }^{5}$ Bioengineering and ${ }^{6}$ Mechanical Engineering Options, California \\ Institute of Technology, Pasadena, California 91125, and Departments of ${ }^{7} \mathrm{Mechanical}$ and Aerospace Engineering and ${ }^{8}$ Biomedical Engineering, University \\ of California, Irvine, Irvine, California 92612
}

In the present study, concurrent treatment with robotic step training and a serotonin agonist, quipazine, generated significant recovery of locomotor function in complete spinal cord-transected mice (T7-T9) that otherwise could not step. The extent of recovery achieved when these treatments were combined exceeded that obtained when either treatment was applied independently. We quantitatively analyzed the stepping characteristics of spinal mice after alternatively administering no training, manual training, robotic training, quipazine treatment, or a combination of robotic training with quipazine treatment, to examine the mechanisms by which training and quipazine treatment promote functional recovery. Using fast Fourier transform and principal components analysis, significant improvements in the step rhythm, step shape consistency, and number of weight-bearing steps were observed in robotically trained compared with manually trained or nontrained mice. In contrast, manual training had no effect on stepping performance, yielding no improvement compared with nontrained mice. Daily bolus quipazine treatment acutely improved the step shape consistency and number of steps executed by both robotically trained and nontrained mice, but these improvements did not persist after quipazine was withdrawn. At the dosage used $(0.5 \mathrm{mg} / \mathrm{kg}$ body weight), quipazine appeared to facilitate, rather than directly generate, stepping, by enabling the spinal cord neural circuitry to process specific patterns of sensory information associated with weight-bearing stepping. Via this mechanism, quipazine treatment enhanced kinematically appropriate robotic training. When administered intermittently during an extended period of robotic training, quipazine revealed training-induced stepping improvements that were masked in the absence of the pharmacological treatment.

Key words: locomotion; quipazine; serotonin; robotics; spinal cord injury; SCI; motor learning; training; plasticity

\section{Introduction}

In recent years, it has become clear that manual training can be used effectively to recover hindlimb motor function in complete spinal animals (Edgerton et al., 1997a, 2001, 2004a,b). For example, adult spinal cats (Lovely et al., 1986, 1990; Edgerton et al., 1991a,b; Hodgson et al., 1994; de Leon et al., 1998; Roy et al., 1998; Rossignol et al., 2002) and, to a lesser extent, adult spinal rats (de Leon et al., 2002; Moshonkina et al., 2002; Timoszyk et al., 2003) that are regularly trained to step can regain the ability to

\footnotetext{
Received Aug. 6, 2004; revised 0ct. 27, 2005; accepted Nov. 5, 2005.

This research was supported by the Christopher Reeve Foundation, National Institute of Child Health and Human Development/National Institute of Neurological Disorders and Stroke Grant HD44830, the National Institute of Neurological Disorders and Stroke Grant NS16333, the Roman Reed Spinal Cord Injury Research Funds, and the University of California, Los Angeles Academic Senate. We thank the following: Hui Zhong for her assistance with animal surgeries; Maynor Herrera for providing excellent animal care; Mark Merlo for designing and fabricating the first prototype of the mouse robot; Niranjala Tillakaratne, John Hodgson, Rebekah Molyneux, and Sharon Zdunowski for their constructive comments and valuable discussions; and an incredible team of undergraduate students, Vivek Agarwal, Nikhil Daga, Gary Hsu, Jee Hur, Dan Popa, Tony Tzeng, Elizabeth Waters, and Yvonne Yaory, for all of their hard work.

Correspondence should be addressed to V. Reggie Edgerton, Department of Physiological Science, University of California, Los Angeles, 621 Charles E. Young Drive South, Los Angeles, CA 90095. E-mail: vre@ucla.edu. D0I:10.1523/JNEUROSCI.1523-05.2005

Copyright $\odot 2005$ Society for Neuroscience 0270-6474/05/2511738-10\$15.00/0
}

generate full weight-bearing treadmill stepping over a range of speeds. The underlying mechanism responsible for their recovery, however, is poorly understood.

The wide availability of genetically modified strains makes the mouse an attractive model for dissecting the adaptive mechanisms of training-induced locomotor recovery. Data to date suggest, however, that, in the absence of any pharmacological intervention, the level of recovery is lower in smaller species such as rats (de Leon et al., 2002) and mice (Guertin, 2004) compared with cats. Although there is one report of significant spontaneous recovery in complete spinal mice without any pharmacological intervention (Leblond et al., 2003), we have been unable to duplicate these observations. The lower recovery in small species may be attributable to the increased difficulty required to manipulate small hindlimbs through kinematically appropriate step cycles, or there may be less adaptive potential in rodents after a spinal cord injury (SCI).

Species differences in training-induced locomotor improvement may be related to the varying difficulty required to apply appropriate spatial and temporal patterns of proprioceptive cues during training in different-sized animals. Training with robotic devices enables locomotor patterns to be imposed with levels of 
precision and consistency that cannot be attained by human hands. In addition to improving training, robotic devices can provide an accurate, quantitative, and immediate assessment of locomotor performance.

Previous studies have shown that quipazine improves treadmill locomotion in adult chronic spinal cats (Barbeau and Rossignol, 1990; Brustein and Rossignol, 1999) and rats (FeraboliLohnherr et al., 1999; Antri et al., 2002), and recently, similar findings were reported for spinal mice (Guertin, 2004). We hypothesized that quipazine acutely elevates the sensitivity of the spinal locomotor circuits to proprioceptive inputs, thereby facilitating locomotor drive patterning when the spinal cord is presented with appropriate sensory cues.

The objectives of this study were threefold: (1) to determine the relative effectiveness of manual and robotic training in improving stepping in complete spinal mice, (2) to determine whether daily, acute administration of quipazine would improve stepping, and (3) to determine whether combining quipazine and robotic training would produce an interaction effect on improving stepping. The results demonstrate that (1) complete spinal mice can be robotically trained to step, whereas manual training, as performed in the present study, is ineffective, (2) quipazine $(0.5 \mathrm{mg} / \mathrm{kg})$ effectively facilitates but does not directly generate stepping, and (3) when applied concurrently, quipazine and robotic step training produce an interaction effect, resulting in stepping performance that exceeds that achieved when either intervention is used alone.

\section{Materials and Methods}

Animals and animal care. The study consisted of five experiments, each consisting of a trained group and a nontrained group. The same trained and nontrained groups were maintained throughout experiments I-IV. Experiment $\mathrm{V}$ used a different set of trained and nontrained mice. For experiments I-IV, 16 Swiss-Webster mice (mean weight of $21.5 \pm 0.3 \mathrm{~g}$ at spinal cord transection) obtained from Charles River Laboratories (Wilmington, MA) were used. For experiment V, an additional 20 SwissWebster mice (mean weight of $25.3 \pm 0.3 \mathrm{~g}$ at spinal cord transection) were used. The mice were housed individually, had access to food and water ad libitum, and were kept on a $12 \mathrm{~h}$ light/dark cycle for the duration of the study.

After each of the two sets of spinal cord transection surgeries (see below), the mice were equally and randomly divided into trained and nontrained groups. The trained groups were provided with various training paradigms, with and without quipazine, throughout the study and were tested periodically to assess their stepping performance. During the corresponding sessions, mice in the nontrained groups were placed into a weight-support harness. The reasons for suspending the nontrained mice were twofold: (1) to approximate the same amount of handling that was given to the trained mice by placing them into the harness, and (2) to unload their hindlimbs, thus eliminating proprioceptive and cutaneous stimuli through the paws, thereby removing the possibility that the nontrained mice received even minimal training during "treatment" sessions. It is extremely unlikely that such short periods of unloading would generate muscle atrophy or similar effects that would be detrimental to their locomotor performance. The nontrained mice received one interval of quipazine treatment during the study and were robotically tested periodically but were never trained. The sequence of experiments and the intervention history of the mice used in experiments I-IV are depicted in Figure 1. All animal procedures used in this study were conducted in accordance with the Animal Care Guidelines of the American Physiological Society and were reviewed and approved by the Animal Research Committee at the University of California, Los Angeles.

Aseptic surgical procedures and postsurgical care. Surgeries for the mice used in experiments I-IV were performed at approximately postnatal day 35 (P35). Surgeries for the mice used in experiment $V$ were performed at approximately P60. Before all surgical procedures, buprenorphine hy- drochloride was administered intraperitoneally $(0.5 \mathrm{mg} / \mathrm{kg}$ body weight $)$ as an analgesic $35-45 \mathrm{~min}$ before the mice were anesthetized. A mixture of ketamine (133 mg/kg body weight) and xylazine $(9 \mathrm{mg} / \mathrm{kg}$ body weight) administered intraperitoneally was used as the anesthetic. Supplemental doses ( $30 \%$ of initial dose) were provided as necessary to maintain a surgical level of anesthesia. During surgery, a watercirculating heating pad was used to maintain body temperature. A skin incision was made along the dorsal midline from approximately $\mathrm{T} 6$ to $\mathrm{T} 9$ to expose the musculature overlying the vertebrae, and a laminectomy was performed from approximately $\mathrm{T} 7$ to $\mathrm{T} 9$. A branch of the thoracodorsal artery in the multilocular adipose tissue above approximately T6 was used as an anatomical landmark. The spinal cord was transected completely at a mid-thoracic level (T7-T9). The location and completeness of the transection were verified visually by two surgeons. Gelfoam was inserted into the gap to ensure complete separation of the proximal and distal stumps (de la Torre and Goldsmith, 1990). The musculature was repositioned, and the wound was closed using 5-0 Dexon internal and 5-0 Ethilon external sutures. After surgery, the mice were placed in an incubator maintained at $\sim 29 \pm 1{ }^{\circ} \mathrm{C}$ and observed until they fully recovered from anesthesia. Baytril ( $40 \mathrm{mg} / \mathrm{kg}$ body weight), a broadspectrum antibiotic, was added to the drinking water for $14 \mathrm{~d}$ after surgery.

Postsurgical care and maintenance procedures were similar to those described previously for spinal cord-injured rats and cats (Roy et al., 1992; Ellegala et al., 1996). The bladders of all spinal mice were expressed manually twice daily to minimize the risk of bladder infection and related complications. After bladder expression, the hindlimbs of the mice were lightly stretched once through a full range of motion to help sustain joint mobility. Food rewards were given to stimulate positive interaction between mouse and handler.

Robotic step training and measurement system. A four-axis robotic system (mouse stepper) was developed to both collect hindlimb position data and guide the hindlimbs through complete step trajectories (see drawing at http://robotics.caltech.edu/jneurosci). The system enables independent, two-dimensional tracking and control of each ankle in the sagittal plane as the mouse steps on a moving treadmill. The mouse stepper consists of four major components: (1) a pair of robotic arms, (2) a motion controller board, (3) a treadmill, and (4) a body-weight support device. The robotic arms, the primary components of the mouse stepper, serve as the interface between the electronics and the mouse. Each robotic arm is composed of a five-bar leg-guidance linkage (Kazerooni and Her, 1994), a pair of motors that drive the linkage (2342-006CR; Micromo Electronics, Clearwater, FL), and a pair of optical encoders that record the rotational position of the motors (HEDM-5500; Agilent, Palo Alto, CA; Micromo Electronics). Forward kinematic equations are used to derive ankle position from the motor angles. The leg-guidance linkage is sized to enable motion tracking and control within a $3.5 \times 3.5 \mathrm{~cm}$ workspace, which is sufficient to accommodate all step trajectories associated with mouse treadmill locomotion. The robotic system was used in two modes. In its active training mode, the robotic arms can drive the hindlimbs through any predetermined pattern within the workspace. In its passive recording mode, the linkages move freely in the workspace, allowing the computer to record independent ankle movements generated entirely by the mouse.

To minimize encumbrance on the mouse hindlimbs, precision bearings and motors with low internal friction are used at all revolute joints. The frictional resistance force at the end effector is estimated to be 0.032 $\mathrm{N}$. The mass inertia of the robotic arm linkage, including its actuators, is estimated to be $\sim 0.4 \mathrm{~g}$ in its reference configuration, the orientation of the robotic arms in which the stepping workspace is initialized. Mass inertia remains within the same order of magnitude of this value for all orientations within the feasible stepping workspace of the mouse. These are practically negligible values. The robotic arms do not critically hinder stepping (see videos at http://robotics.caltech.edu/jneurosci). All mice used in the study were tested under the same conditions on the mouse stepper.

A 4-inch-wide industrial conveyor (GUF-P 2000; MK Automation, Bloomfield, CT) was modified for use as a treadmill. The stock belt was replaced with a slightly tacky treadmill belt that provided a slip-free 


\section{Timeline - Experiments I-IV}

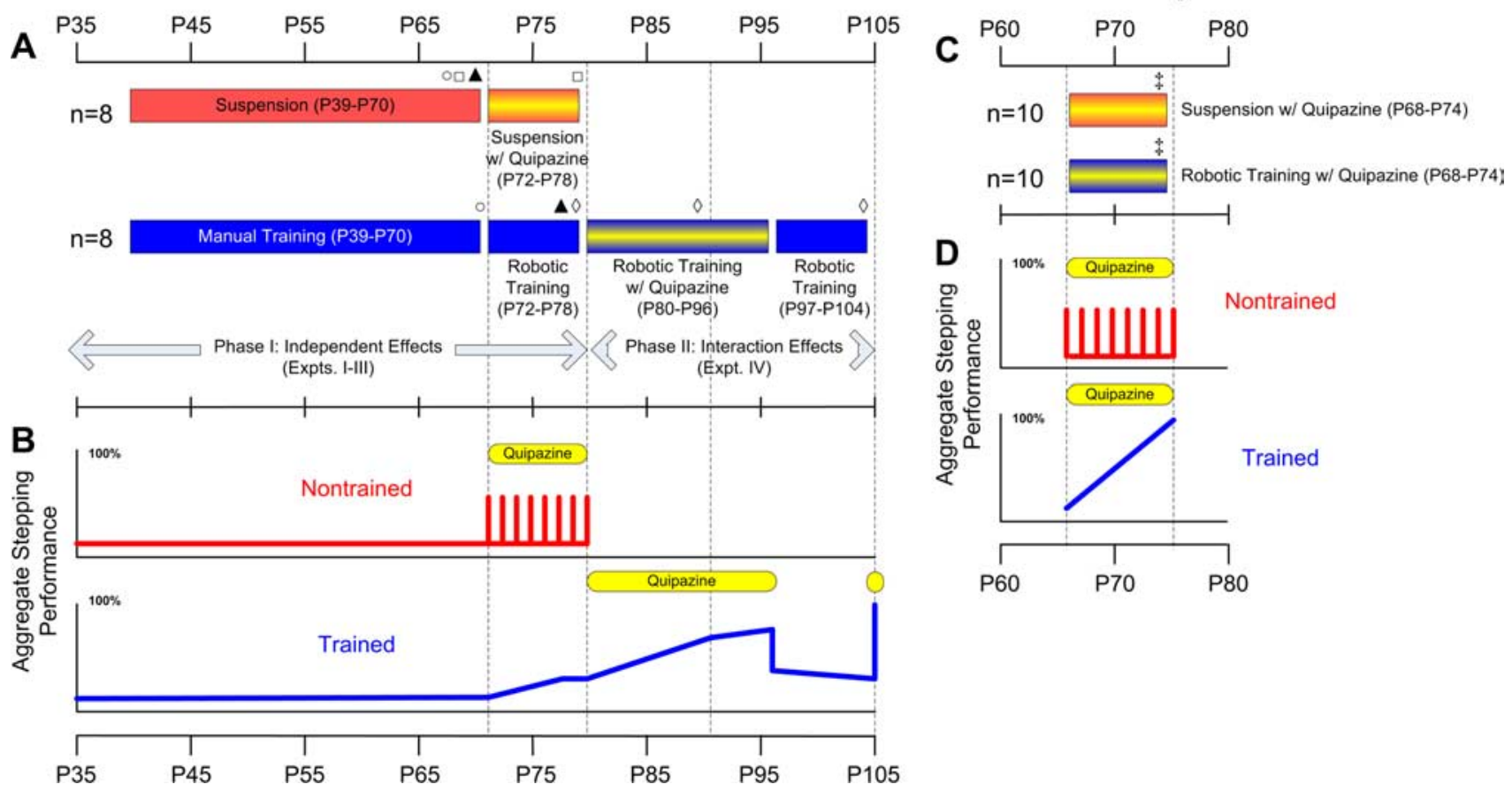

\section{Timeline - Experiment V}

Figure 1. Experimental timeline. The sequence of experiments conducted on the step trained (blue bars) and nontrained (red bars) groups are shown for experiments I-IV ( $\boldsymbol{A}$ ) and experiment V (C). Test dates are indicated by the vertical dashed lines. Yellow stripes denote the periods during which quipazine was administered as a single bolus daily. Time course plots of the aggregate stepping performance of the trained (blue line) and nontrained (red line) mice are shown for experiments I-IV (B) and experiment V (D). Aggregate stepping scores were determined as a qualitative weighting of the three stepping measurements used in the study (number of steps, step rhythm, and step shape consistency) and were normalized against the best stepping observed during each group of experiments (denoted as 100\%). Number of steps performed was the predominant factor in determining the aggregate score. During the periods labeled as "Suspension," the nontrained mice were placed in the harness with their hindlimbs unloaded for $15 \mathrm{~min} / \mathrm{d}$. This amount of unloading is extremely unlikely to have adversely affected stepping ability. Open circles, open squares, and filled triangles denote the time points used for examining the effects of manual training, quipazine treatment, and robotic training, respectively, in experiments I-III. It is important to note that the baseline scores against which these treatments were compared are time independent and represent the maximal performance that can be expected for nontrained, untreated mice. Open diamonds denote the time points compared in the longitudinal experiment IV. Double daggers denote the time point studied in the parallel experiment V.

stepping surface without irritating the skin on the paws, an injury commonly observed with other belt materials. Mice are placed into the mouse stepper using a cone-shaped cloth harness that is magnetically secured to the weight-support system. The hindlimbs are connected to the robotic arms using a drawstring loop attachment. Both ends of a rounded rubber string are fed through an eyelet in the linkage end effector, forming a loop through which the hindpaw is placed. The diameter of the eyelet is sufficient to pass both ends of the string but small enough to resist axial slipping when the string is drawn tight. The thickness of the rubber prevents the ankle from coming into direct contact with the metal linkage, and its elasticity allows an appropriate amount of rotation and lateral motion while the ankle is guided through sagittal trajectories.

The robotic system enhanced both locomotor training and recording, providing several benefits: (1) it enabled precise control of hindlimb movements, (2) it ensured consistent application of a training protocol between mice and across training sessions, (3) it provided a quantitative record of the training history of each mouse, (4) it granted immediate access to the data, and (5) it facilitated application of quantitative analysis techniques.

Manual training. During manual training, the mice were placed into the weight-support harness and oriented in a manner conducive to hindlimb bipedal locomotion. Manual training protocols vary among laboratories and are inherently difficult to describe. The method used in this study mimics strategies that have been particularly effective in both cats (Lovely et al., 1986; de Leon et al., 1998, 1999a) and rats (de Leon et al., 2002), in which a human trainer grasps the hindlimbs and manipulates them through a trajectory similar to that of normal stepping. Similar strategies are routinely used in physical therapy for human patients with diminished locomotor ability (Wernig et al., 1999; Behrman and Harkema, 2000; Dietz, 2001; Harkema, 2001; Dietz and Colombo, 2004). For the manual training used in this study, each mouse was positioned over a moving treadmill and induced to bear some weight. While oriented in this manner, human trainers used cotton swabs to manipulate the hindlimbs through kinematically appropriate stepping patterns. As consistently as possible, the cotton swabs were placed alternately on the ventral surface of the paw, against the back of the heel, and on the dorsal surface of the paw, to lift the paw off the treadmill, to guide the paw forward through swing, and finally to properly place the paw into stance. Because of the small size of the mice, the cotton swabs enabled more precise control of the positioning of the hindlimbs than using the trainer's fingers. Noxious stimuli, such as pinching of the tail, were not used.

Robotic training. During robotic training, the mice were placed into the weight-support harness and oriented in a manner conducive to hindlimb bipedal locomotion. Robotic training cycled between 30 s periods during which the robotic arms actively guided the hindlimbs through a predetermined trajectory using an alternating gait (active training mode), and $30 \mathrm{~s}$ periods during which the robotic arms passively tracked the hindlimb motions generated by the mouse (passive recording mode). The purpose of this cycling was to give the mice opportunities to explore stepping patterns other than the trained trajectory and to prevent the onset of "learned helplessness" (Drugan et al., 1981; Grau et al., 1998).

The training pattern implemented by the mouse stepper was adapted from bipedal stepping patterns recorded from a group of neonatally transected mice of the same age and size as the mice used in this study [step height, $14.8 \mathrm{~mm}$; step length, $24.6 \mathrm{~mm}$; frequency, 1 Hz (http:// robotics.caltech.edu/jneurosci)]. Neonatally transected mice spontaneously recover functional stepping without pharmacological or mechanical assistance. Their stepping patterns are likely more representative of successful spinal stepping than patterns taken from intact, quadrupedally stepping mice.

Quipazine treatment. Quipazine, a broad-spectrum serotonin agonist, was used to facilitate stepping. We conducted a dose-response study 
A. Nontrained Mouse w/o Quipazine

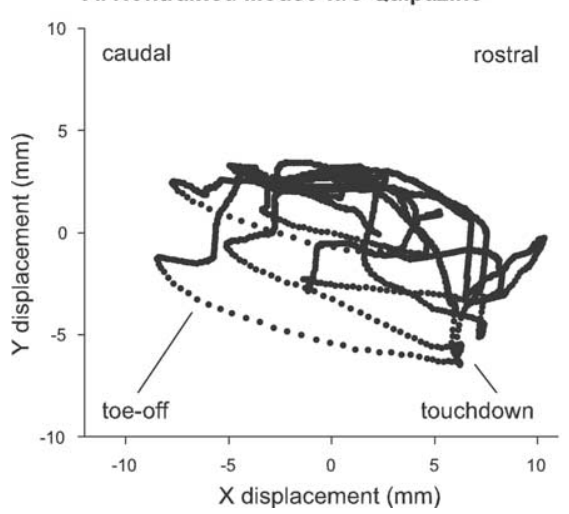

B. Robotically Trained Mouse w/o Quipazine

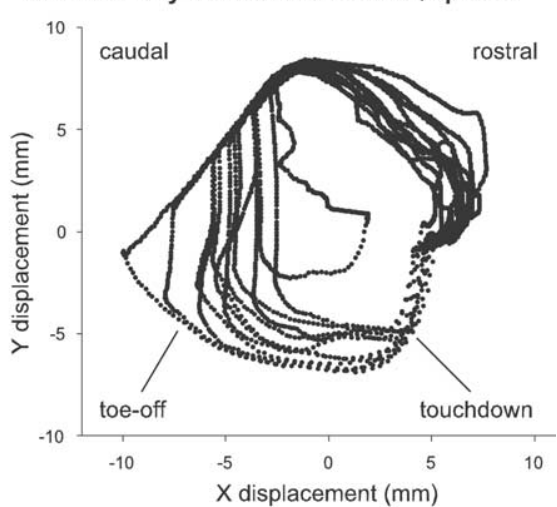

speed of $3 \mathrm{~cm} / \mathrm{s}$. Position data were recorded at $400 \mathrm{~Hz}$ using a custom acquisition program written in the Matlab (MathWorks, Natick, MA) development environment. In addition to the robot data, we captured video footage of both the left and right sides of each mouse during testing and maintained a log of qualitative observations. The number of steps executed by each mouse during the test session was counted, and their step rhythm and step shape consistency, stepping parameters that should intuitively improve with locomotor recovery, were quantitatively evaluated using fast Fourier transform (FFT) and principal components analysis (PCA) algorithms, as described below. Locomotor performance scores are reported as the mean $\pm \mathrm{SE}$ value. Both single sample and independent samples $t$ tests were used to assess the statistical significance of the results. Single sample $t$ tests were used to compare the stepping performance of the trained or pharmacologically treated mice in experiments I-III with

Nontrained Mouse w/ Quipazine
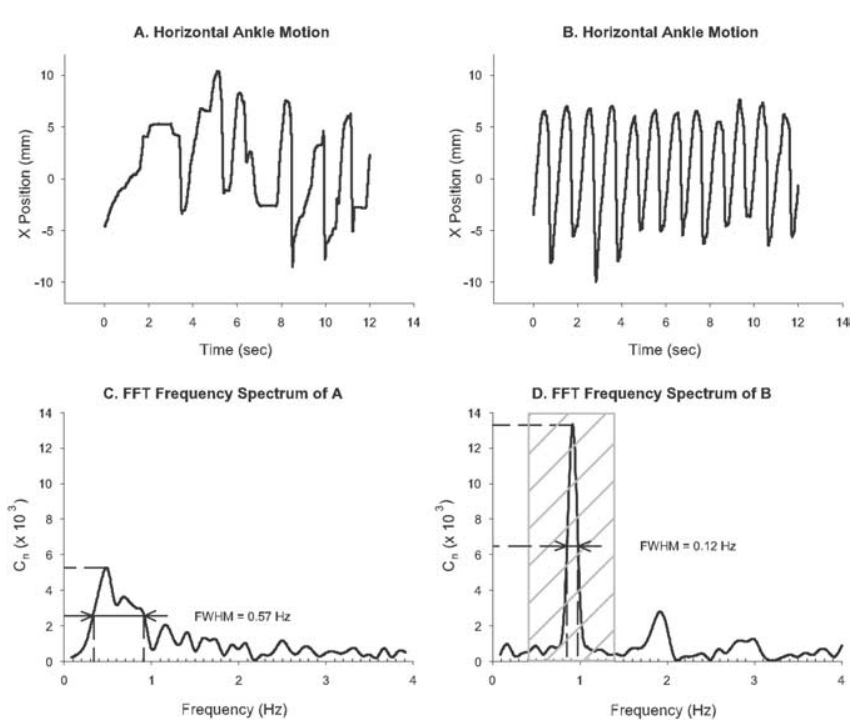

Figure 3. Fast Fourier transform analysis. FFT analysis provides information about step rhythm. Twelve seconds of horizontal ankle motion during stepping are shown for a nontrained mouse given quipazine that stepped arrhythmically $(\boldsymbol{A})$ and for a trained mouse given quipazine that stepped rhythmically $(\boldsymbol{B})$. The corresponding frequency spectrum and the FWHM of the peak at the primary stepping frequency for $\boldsymbol{A}$ and $\boldsymbol{B}$ are shown in $\boldsymbol{C}$ and $\boldsymbol{D}$, respectively. Lower values of FWHM correspond to more rhythmic stepping. For successful spinal stepping on a treadmill at $3 \mathrm{~cm} / \mathrm{s}$, the peak corresponding to the primary stepping frequency lies between 0.4 and $1.4 \mathrm{~Hz}$ ( $\boldsymbol{D}$, crosshatched region). $\mathrm{C}_{\mathrm{n}}$ represents the number of incidences during a test session that the mouse stepped at a particular frequency.

using quipazine doses ranging from 0.2 to $2.0 \mathrm{mg} / \mathrm{kg}$ body weight administered intraperitoneally. At all of the doses tested, quipazine did not directly generate stepping in the absence of treadmill-induced sensory stimuli. Based on these results, a dosage of $0.5 \mathrm{mg} / \mathrm{kg}$ body weight was selected, which was the smallest dose that evoked robust stepping when the mouse was placed on the moving treadmill belt. This is the same dosage that has been reported to activate the spinal locomotor network in adult spinal rats (Feraboli-Lohnherr, 1999). During the specified periods, quipazine was administered $15 \mathrm{~min}$ before each treatment or testing session.

Testing protocol. Testing was performed at the time points shown in Figure $1 \mathrm{~A}$. Before each testing session, the mice were given a $2 \mathrm{~min}$ "warm-up" period. The mouse stepper was then used in a passive recording mode to track the ankle position of each leg for $2 \mathrm{~min}$ at a treadmill the baseline scores assigned to the nontrained, untreated mice. Independent samples $t$ tests were used to contrast the effects of the different treatment strategies used during experiments IV and V.

Criteria for successful stepping. Video footage and plots of ankle position data were used to identify and count the number of steps performed by each mouse. Steps were identified based on predetermined criteria for step length, height, duration, and degree of interlimb coordination. The $12 \mathrm{~s}$ stepping interval containing the most steps was recorded for subsequent analyses. Both plantar and dorsal steps were accepted. Better performing subjects performed primarily plantar steps, whereas poorer performing subjects exhibited dorsal steps and paw drag. Examples of different quality step trajectories are depicted in Figure 2.

FFT analysis. Given their periodic nature, locomotor stepping cycles are well suited for FFT analysis (Tukey and Cooley, 1965). The FFT spectrum of ankle position during the best $12 \mathrm{~s}$ interval of stepping for each mouse was determined for each test session. Peaks in the FFT spectrum correspond to the most common stepping frequencies exhibited during the test interval (Fig. 3C,D). Sharp, distinct spikes correspond to very consistent, rhythmic stepping (Fig. $3 B, D$ ). Broad peaks, or the lack of a dominant peak, correspond to inconsistent, arrhythmic stepping and are characteristic of frequent stumbling and paw drag (Fig. $3 A, C$ ). Because constant treadmill speed requires mice to step rhythmically, we expected that the width of the dominant peak would progressively decrease as more aggressive treatment strategies were applied. To examine step rhythm, we measured the full-width at half-maximum (FWHM) of the tallest peak in the FFT spectrum between 0.4 and $1.4 \mathrm{~Hz}$. FWHM is the width of the selected peak at half its maximum amplitude and is measured in Hertz, the same unit used for stepping frequency. Note that lower values of FWHM indicate better relative step rhythm. At the treadmill speed used in this study $(3 \mathrm{~cm} / \mathrm{s})$, the expected stepping frequency, i.e., the location of the tallest peak, is $\sim 1 \mathrm{~Hz}$. The range of stepping frequencies from which the measured peak was selected $(0.4-1.4 \mathrm{~Hz})$ accounts for variations in mouse limb lengths and small fluctuations in treadmill speed. Peaks at lower frequencies are inconsistent with successful stepping and were ignored. Peaks at higher frequencies approach the physical limit of mouse hindlimb motion and generally were not observed. A minimum of three steps was required to perform FFT analysis. When stepping was so poor that no dominant peak was found or when the mouse did not perform at least three steps, a default FWHM value of $1.2 \mathrm{~Hz}$ was assigned. This value is slightly larger than the highest FWHM values that we measured empirically $(\sim 0.95 \mathrm{~Hz})$. We found that the FWHM of the dominant peak within the normal range of stepping frequencies provided a key measure of stepping performance.

$P C A$. Improved spatial stepping consistency was characterized by increasingly consistent repetition of a nominal trajectory. PCA is a multivariate analysis technique that picks out patterns in a dataset and reduces the dimensionality of the data without significant loss of information 

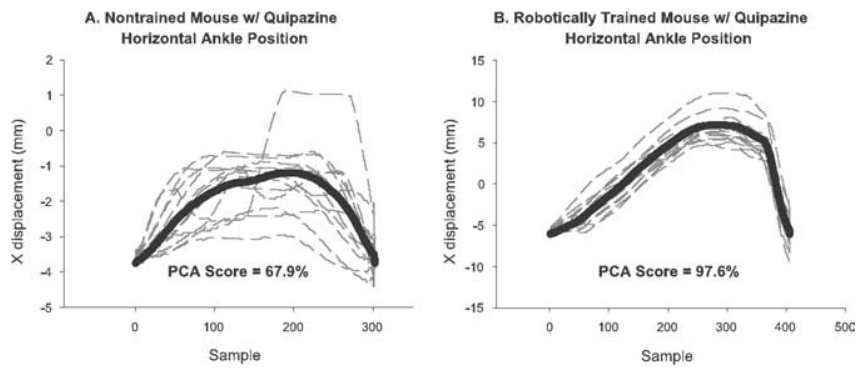

Figure 4. Principal component analysis. The first principal component from a PCA identifies the most representative step pattern executed by a mouse. A mouse with a high PCA percentage for its first principal component stepped with a more consistent step shape than a mouse with a lower PCA percentage score. Plots of several $x$ trajectories (dashed lines) and their corresponding first principal component (solid lines) are shown for a quipazine-treated nontrained mouse $(\boldsymbol{A})$ and for a quipazine-treated trained mouse $(\boldsymbol{B})$. The corresponding PCA percentages, $67.9 \%$ $(\boldsymbol{A})$ and $97.6 \%(\boldsymbol{B})$, respectively, indicate that quipazine facilitated greater improvement in spatial stepping consistency in trained than nontrained mice. Note also from the different scales of the $x$-displacement (ordinate) axis that trained mice generally took much longer steps than nontrained mice.

(Dunteman, 1989). Given a series of step trajectories, PCA extracts the fundamental trajectory as the first principal component (Fig. 4). The PCA score reported here is the percentage of the total variance that is captured by the first principal component. Hence, the higher the PCA score, the more consistent the stepping.

The raw stepping data were preprocessed for PCA. First, the successful step cycles from the selected best $12 \mathrm{~s}$ intervals of stepping were isolated and separated into their $x$ and $y$ components. Each step component was resampled to a consistent number of data points per step, thus removing the temporal information. The data were then arranged into two $m \times n$ matrices, with each column containing the data for a single step and each row containing the interpolated position values at each time step:

$x$ component of steps $y$ component of steps

$\left[\begin{array}{ccccc}x_{1,1} & x_{1,2} & \cdots & \cdots & x_{1, n} \\ x_{2,1} & x_{2,2} & & & x_{2, n} \\ \vdots & & \ddots & & \vdots \\ \vdots & & & \ddots & \vdots \\ x_{m, 1} & x_{m, 2} & \cdots & \cdots & x_{m, n}\end{array}\right]\left[\begin{array}{ccccc}y_{1,1} & y_{1,2} & \cdots & \cdots & y_{1, n} \\ y_{2,1} & y_{2,2} & & & y_{2, n} \\ \vdots & & \ddots & & \vdots \\ \vdots & & & \ddots & \vdots \\ y_{m, 1} & y_{m, 2} & \cdots & \cdots & y_{m, n}\end{array}\right]$

A Matlab script was written to identify the principal components of each dataset and to calculate the PCA score. A minimum of three successful steps was required to conduct a statistically significant PCA. Mice that could not perform at least three steps in any $12 \mathrm{~s}$ interval were assigned a PCA value of $35 \%$, which is approximately the lowest score that we obtained for mice that could perform at least three steps.

Baseline performance scores. In this study, the performance of nontrained, untreated (no quipazine) mice served as the standard against which the effectiveness of robotic training and quipazine treatment were compared. Typically, however, the nontrained, untreated mice were unable to perform the minimum three steps in a $12 \mathrm{~s}$ interval required to perform FFT analysis or PCA. For the purpose of defining a baseline standard, we assigned the following scores for nontrained, untreated spinal mice: steps, 16; FFT, 1.2 Hz; PCA, 35.0\%. The value selected for the baseline number of steps is the average number of steps performed by nontrained, untreated mice (see Results). The baseline FFT and PCA values are the values assigned for mice that could not perform at least three successful steps in a $12 \mathrm{~s}$ interval (discussed above). Consistent with findings in adult spinal rats (Commissiong and Sauve, 1993; Molinari and Petrosini, 1993), in the absence of treatment, complete spinal SwissWebster mice (P39) do not spontaneously recover locomotor ability. Hence, these baseline scores are independent of time after lesion.

\section{Results}

\section{Experiment I: effects of manual training}

The purpose of experiment I was to determine whether manual training could be used to improve locomotor performance after a complete mid-thoracic spinal cord transection in mice. Manual training was performed for $15 \mathrm{~min} / \mathrm{d}, 5 \mathrm{~d}$ /week for 5 weeks beginning at P43, $4 \mathrm{~d}$ after the spinal cord transection surgery. On the sixth day of each of the first 4 weeks, the hindlimbs of both the trained and nontrained mice were attached to the robotic arms for acclimatization. On the last day of the experiment, P71, the hindlimb movement patterns of all of the mice were recorded for 2 min with the robot operating in a passive recording mode. Quipazine was not administered at any time during experiment I.

After 5 weeks of manual training, the locomotor performance of the trained mice was not statistically different from that of the nontrained mice. Mice in both groups were essentially unable to initiate a swing phase and thus dragged their paws on the treadmill belt. On the isolated occasions that they were able to bring a paw forward, they typically landed on the dorsal surface of the paw, a proprioceptive trigger for stumbling and collapse. The mean total number of steps performed in a 2 min test period in the trained mice was $16.0 \pm 5.1$ compared with $15.8 \pm 5.5$ for the nontrained mice. Neither PCA nor FFT analysis could be performed at this juncture because the animals were unable to perform the critical number of successful steps required to implement these measures. Manual training did not produce a statistically significant improvement compared with no training.

\section{Experiment II: effects of robotic training}

The purpose of experiment II was to determine whether robotic training could be used to facilitate locomotor improvement in spinal mice. The mice that were manually trained in experiment I from P43 to P70 were used for this experiment and underwent robotic training for $15 \mathrm{~min} / \mathrm{d}$ between P71 and P78. On P79, the hindlimb movement patterns of the trained mice were recorded for $2 \mathrm{~min}$, with the robot operating in a passive recording mode. Quipazine was not administered at any time during experiment II.

Compared with the assigned baseline scores for nontrained spinal mice that basically did not step in experiment I, robotic training of the previously manually trained rats in experiment I generated statistically significant improvement in locomotor performance (Table 1). At P79, the mean number of steps executed by the robotically trained mice had increased from 16 to $31.6 \pm 7.1(p=0.023)$. Based on FFT analysis, their mean step rhythm score had improved from 1.2 to $0.81 \pm 0.15 \mathrm{~Hz}(p=$ $0.011)$. Likewise, PCA showed that their mean step shape consistency score had improved from 35.0 to $76.4 \pm 3.8 \%(p<0.001)$. Therefore, robotic training improved stepping performance.

\section{Experiment III: effects of quipazine treatment}

The purpose of experiment III was to determine whether daily quipazine treatment could be used to facilitate locomotor improvement in spinal mice. During the same period that the trained mice were robotically trained, P71-P78, the nontrained mice were administered a bolus dose $(0.5 \mathrm{mg} / \mathrm{kg})$ of quipazine intraperitoneally daily. After quipazine was administered, the mice were suspended for $\sim 15 \mathrm{~min}$ in the weight-support harness to provide them with similar sensory stimuli as that given to the robotically trained mice, which were similarly supported during training. On P79, the hindlimb movement patterns of the nontrained mice were recorded for $2 \mathrm{~min}$, with the robot operating in a passive recording mode.

Within 5 min of the initial quipazine treatment, mice that were previously unable to step were able to execute long periods of uninterrupted, successful stepping at treadmill speeds ranging from 3 to $10 \mathrm{~cm} / \mathrm{s}$ (see videos at http://robotics.caltech.edu/ 
Table 1. Quipazine and robotic training independently improve stepping performance

\begin{tabular}{|c|c|c|c|}
\hline & Baseline & Experiment II & Experiment III \\
\hline & NT, -0 & $\mathrm{RT},-\mathrm{Q}$ & $\mathrm{NT},+\mathrm{Q}$ \\
\hline No. of steps & 16.0 & $31.6 \pm 7.1^{c}$ & $55.1 \pm 13.0^{d}$ \\
\hline FFT FWHM (Hz) ${ }^{a}$ & 1.20 & $0.81 \pm 0.15^{c}$ & $0.96 \pm 0.12$ \\
\hline $\mathrm{PCA}(\%)^{b}$ & 35.0 & $76.4 \pm 3.8^{c}$ & $77.4 \pm 3.9^{d}$ \\
\hline
\end{tabular}

NT, Nontrained; RT, robotically trained; $+Q$, treated with quipazine; -0 , not treated with quipazine. FWHM is of the dominant peak in the FFT spectrum between 0.4 and $1.4 \mathrm{~Hz}$. SEM values are reported.

${ }^{a}$ Lower values of FWHM correspond to improved step rhythm.

${ }^{b}$ Higher values of PCA percentage correspond to improved step shape consistency, up to a practical maximum of $\sim 90 \%$.

'Based on all three measures of stepping ability, i.e., number of steps performed ( $p<0.05$ ), step rhythm ( $p<$ $0.05)$, and step shape consistency $(p<0.001)$, mice that received robotic training performed statistically better than nontrained, untreated mice.

${ }^{d}$ Mice administered quipazine statistically improved the number of steps performed $(p<0.05)$ and step shape consistency $(p<0.001)$ compared with nontrained, untreated mice. Quipazine did not affect step rhythm.

jneurosci). No air stepping was observed. The mice only stepped when their paws were placed on the moving treadmill belt. Qualitatively, the most significant improvements of the quipazinemediated stepping were (1) robust toe-off into swing phase, (2) pronounced, perhaps exaggerated, toe extension, and (3) frequent plantar paw placement. Although quipazine acutely improved stepping immediately after each treatment, no persistent or progressive enhancements of stepping ability were obtained with repeated quipazine treatment alone.

Compared with the baseline scores assigned for these same mice earlier in the study when they were the nontrained group (experiment 1, P43-P70) that basically did not step, quipazine treatment acutely generated statistically significant improvements in number of steps performed and step shape consistency on P79 (Table 1). At P79, the mean number of steps executed by the quipazine-treated mice had increased from 16.0 to $55.1 \pm$ $13.0(p=0.046)$. Similarly, PCA showed that their mean step shape consistency score had improved from 35.0 to $77.4 \pm 3.9 \%$ $(p<0.001)$. Unlike robotic training, however, quipazine treatment did not statistically improve step rhythm. Therefore, quipazine treatment improved two of the three aspects of stepping performance measured.

\section{Experiment IV: interaction effects of combining robotic training and quipazine treatment}

Having established that robotic training and quipazine treatment were each able to generate locomotor improvement in spinal mice, the goal of experiment IV was to determine whether combining the treatments would produce a net interaction effect that was greater than either of the independent effects. To maximize the use of the animals, we implemented an experimental plan in which the trained mice were continuously robotically trained while quipazine was repeatedly administered and withdrawn. The goal of this procedure was to observe whether the stepping performance of the mice would fluctuate when they were sequentially administered or not administered quipazine.

The mice used for experiment IV were the same trained mice used sequentially in both experiments I and II that had been manually trained from P43 to P70 (experiment I) and then robotically trained from P71 to P79 (experiment II). Between P80 and P96, these mice were provided a daily regimen combining quipazine and robotic training using the same procedures described above (Fig. 1A). Stepping performance was tested after quipazine administration on P91. Between P97 and P104, quipazine was withheld, while robotic training continued. The mice then were tested both before and after a bolus dose of quipazine on P105.

The time course variation in the number of steps executed by the mice is consistent with an interaction effect (Fig. 5A). At P79, after the first period of robotic training without quipazine, the mice executed $31.6 \pm 7.1$ steps. At P91, during the combination treatment period, the mice performed 78.2 \pm 20.0 steps in the 2 min test interval, a statistically significant improvement $(p=$ $0.015)$. At P105, after the second period of robotic training without quipazine, the number of steps decreased to $24.3 \pm 21.6$ steps, a statistically significant decline compared with that at P91 ( $p=$ 0.021) and similar to the number of steps performed at P79. After being given the additional bolus dose of quipazine at P105, their number of steps again markedly increased to $146.0 \pm 16.9$ ( $p<$ 0.001 compared with before quipazine), marking their best performance of the study ( $p=0.013$ compared with P91).

The step shape consistency results also support an interaction effect (Fig. 5B). At P79, the mean PCA score of the mice was $76.4 \pm 3.8 \%$. As a result of the combined treatment, their score statistically increased to $87.1 \pm 3.2 \%(p=0.031)$. The score decreased to $55.0 \pm 9.7 \%$ when quipazine was withheld ( $p=$ 0.007 compared with $\mathrm{P} 91)$ but rose again to $78.5 \pm 5.5 \%$ ( $p=$ 0.035 compared with before quipazine) after the bolus dose of quipazine at P105.

In contrast to number of steps performed and step shape consistency, the step rhythm scores for the mice improved steadily throughout the course of treatment (Fig. 5C). The mean FFT score of the mice decreased continuously from $0.81 \pm 0.15 \mathrm{~Hz}$ at P79 to $0.15 \pm 0.02 \mathrm{~Hz}$ at P105 $(p=0.001)$. These results are consistent with the results of experiment III, which indicate that quipazine has a smaller effect on step rhythm compared with robotic training.

\section{Experiment V: quipazine treatment versus robotic training with quipazine treatment}

To further examine the existence of an interaction effect, we compared the effects of quipazine treatment alone with those of the combination treatment (quipazine with robotic training) in an additional set of mice. For experiment V, 20 mice were spinally transected at approximately P60 (mean weight, $25.3 \pm 0.3 \mathrm{~g}$ ) and were equally and randomly divided into a trained and a nontrained group. Between P68 and P74, the trained mice were provided a daily regimen combining quipazine and $15 \mathrm{~min} / \mathrm{d}$ robotic training. During the same interval, the nontrained mice were administered daily bolus doses of quipazine $(0.5 \mathrm{mg} / \mathrm{kg})$ and were suspended in the weight-support harness for $15 \mathrm{~min} / \mathrm{d}$. At P75, the stepping performance of each group was evaluated for $2 \mathrm{~min}$ using the robot in a passive recording mode.

At P75, the group that received the combination treatment outperformed the group that was administered quipazine only. The combination treatment mice executed more steps (32.9 \pm $7.0)$ than the quipazine only mice $(17.1 \pm 6.0)(p=0.050)$. The combination treatment mice had a lower FFT score $(0.12 \pm 0.01$ $\mathrm{Hz})$ than the quipazine only mice $(0.66 \pm 0.18 \mathrm{~Hz})$, indicating that they stepped more rhythmically $(p=0.006)$. PCA also showed that the combination treatment mice $(83.9 \pm 3.8 \%)$ displayed a more consistent step shape than the quipazine only mice $(60.7 \pm 8.9 \%)(p=0.015)$. These results indicate that the locomotor enhancement mediated by combining robotic training with quipazine was larger than that of quipazine treatment alone. 


\section{Summary of results}

Figure $1 B$ summarizes the principal findings of this study, which are as follows: (1) manual training did not affect stepping ability, (2) robotic training significantly improved stepping performance, (3) daily acute quipazine treatment transiently facilitated locomotor improvement but did not generate a long-lasting effect on stepping ability, (4) stepping performance improved further when robotic training was combined with concurrent quipazine treatment, and (5) acute quipazine treatment of robotically trained mice revealed training-induced stepping improvements that were masked in the absence of drug treatment.

\section{Discussion \\ Quipazine facilitated spinal processing of sensory information associated with weight-bearing stepping}

Complete mid-thoracic spinal cord transection induces a substantial loss of spinal cord serotonin content (Anden et al., 1964; Laporte et al., 1995). One pharmacological strategy for treating SCI is to recreate an intraspinal chemical environment that enables the spinal circuitry to generate functional locomotor patterns. Systemic and intrathecal applications of noradrenergic (Barbeau and Rossignol, 1991; Chau et al., 1998; Giroux et al., 2001), dopaminergic (Goldberger, 1977; Barbeau and Rossignol, 1991), serotonergic (Feraboli-Lohnherr et al., 1999; Machacek et al., 2001; Antri et al., 2002), and glycinergic (Edgerton et al., 1997b; de Leon et al., 1999b) drugs have been effective in eliciting locomotor patterns in spinal cats, rats, and mice. We observed that quipazine enabled hindlimb bipedal stepping in complete spinal mice, an observation consistent with findings reported by Guertin (2004). Quipazine and another serotonin agonist, $m$-chloropiperazine, have been shown to facilitate locomotion in cats (Barbeau and Rossignol, 1990) and rats (Kim et al., 2001), respectively, and similar improvement was reported when serotonergic embryonic raphe cells were implanted in spinal rats (Feraboli-Lohnherr et al., 1997; Kim et al., 1999; Dumoulin et al., 2000; Ribotta et al., 2000).

The mechanism by which serotonin mediates locomotor improvement after SCI is not well understood. Although it has been suggested that serotonin induces fictive locomotion (Cazalets et al., 1992; Grillner et al., 2001), the present results indicate that serotonin facilitates, but does not generate, stepping in the spinal mouse in vivo. Spinal mice administered quipazine did not "air step." On the contrary, quipazine-treated mice only initiated stepping when triggered by sensory stimuli derived from placing the hindlimbs on the moving treadmill belt.

Combinations of therapeutic treatments may be more beneficial than individual treatments. When quipazine was administered concurrently with weight-bearing step training, the performance of the spinal mice exceeded that obtained with either quipazine treatment or robotic training alone. Although spinal mice markedly improved their stepping ability after 1 week of robotic training, their rate of improvement and overall stepping performance further increased when robotic training and quipazine were combined (combination treatment). The data indicate that this additional improvement was mediated primarily by quipazine treatment, not by extended robotic training, because stepping ability immediately regressed when quipazine was withdrawn. This transient nature of quipazine-mediated stepping facilitation is consistent with findings describing a decline in locomotor performance after termination of chronic intrathecal quipazine treatment in spinal rats (Antri et al., 2002).

Analysis of the stepping data confirmed that each treatment made distinct contributions to the net locomotor scores. In experiment IV, consistent with the findings in experiments II and III, step rhythm improved steadily with continued robotic training, but step shape consistency fluctuated in accordance with quipazine administration and withdrawal. The combination treatment produced a positive interaction effect that was superior to robotic training alone.

The results of the parallel comparison in experiment $\mathrm{V}$ also support an interaction effect. After 1 week of treatment, the number of steps, step rhythm, and step shape consistency of mice given the combination treatment were significantly better than those of mice administered quipazine only. Thus, the combination treatment was more successful than quipazine treatment alone.

Despite the difference in the ages of the mice at spinal transection, both experiment IV (P35) and experiment V (P60) demonstrated an interaction effect between robotic training and quipazine treatment on stepping performance. Thus, the specific age of the mice at the time of each experimental intervention was most likely not the critical factor responsible for producing the observed outcomes.

When administered in conjunction with weight-bearing stepping, quipazine may modulate the relative levels of sensory information "perceived" by the spinal cord, favoring interneuronal pathways that are linked to proprioceptive and cutaneous stimuli. This putative sensory modulation role is consistent with the presence of 5-HT receptors in the dorsal horn of the lumbosacral spinal cord (Liu et al., 2002). Furthermore, numerous findings associate 5-HT with sensory input modulation (Machacek et al., 2001; Meuser et al., 2002; Miquel et al., 2002; Shay and Hochman, 2002; Bosco et al., 2003; Hains et al., 2003). In intact cats, monoamine release selectively increases the excitability of some reflex circuits but decreases the excitability of others, e.g., potentiating transmission from group I spindle fibers and tendon organs (Edgley et al., 1988; Bras et al., 1990) while depressing transmission from nociceptors and group II fibers (Headley et al., 1978; 
Fleetwood-Walker et al., 1985). The near absence of serotonin caudal to a complete spinal cord lesion may limit the ability of the spinal cord to discriminate sensory inputs and may contribute to the spasticity associated with spinal injury. During locomotion, quipazine may restore appropriate sensory processing, "tuning" the spinal cord to relevant sensory cues while suppressing extraneous inputs such as pain.

Serotonergic agonists hyperpolarize the action potential threshold (Wikstrom et al., 1995; Grillner et al., 2001; Hill et al., 2003) and shorten the duration of afterhyperpolarization (Fedirchuk and Dai, 2004). These changes frequently bring the membrane potentials of spinal neurons near the threshold required to generate plateau potentials, which have been hypothesized to be the basis for locomotor drive potentials. In this hyperexcitable state, even minimal amounts of sensory input can initiate plateau potentials (Kiehn et al., 1996; Gorassini et al., 1999). Thus, short-term modulation of the membrane potential may be a mechanism by which quipazine acutely facilitates locomotor recovery.

By repeatedly activating sensory circuits and the interneurons to which they project, chronic, consistent training of spinal cordinjured subjects may continue to modify spinal locomotor circuits even after functional improvements are no longer apparent. In the present study, quipazine treatment may have revealed masked positive effects of weight-bearing step training. During the longitudinal robotic training experiment (experiment IV), the stepping ability of mice administered the combination treatment rapidly declined to their pre-quipazine performance when quipazine was withdrawn and remained at that level even when robotic training was continued. Initially, this suggested that the positive effects of robotic training had plateaued. At the end of the extended robotic training period, however, an additional bolus dose of quipazine immediately increased overall stepping ability, eclipsing the performance after the combination treatment period. Because the mice were not administered quipazine during the $9 \mathrm{~d}$ preceding this final test, chronic quipazine treatment effects were ruled out. Consequently, the observation that the same quipazine treatment elicited a substantially greater level of performance after than before the additional robotic training suggests that the acute quipazine treatment may have facilitated masked effects of chronic step training.

For studies in which pharmacological treatments are investigated for improving motor function after an injury, the present results indicate that repeated handling of subjects in a manner that consistently activates relevant sensory pathways may be critical to generating recovery. These findings support the hypothesis that spinal learning is highly sensitive to specific spatial and temporal patterns of sensory cues and suggest that providing appropriate types and levels of sensory information during step training is essential for optimal recovery after an SCI. In contrast, poorly designed or poorly implemented training may yield no effect and may even impair locomotor performance.

\section{Manual training did not improve stepping performance}

Adult cats (Lovely et al., 1990; Edgerton et al., 1991a,b; de Leon et al., 1998; Rossignol et al., 2002) and rats (de Leon et al., 2002; Moshonkina et al., 2002) that are completely spinalized at a midto low-thoracic level can relearn to step via manual training. Trainer-assisted guidance of the hindlimbs through a kinematically appropriate trajectory, the manual training method used here, did not improve locomotor performance in complete spinal mice. This was probably attributable, in part, to our inability to control small mouse hindlimbs with sufficient consistency. It is possible, although unlikely, that other methods of manual training would yield different results.

No significant recovery of stepping ability was observed in either the nontrained or manually trained mice. These observations contrast with those of Leblond et al. (2003), who described spontaneous locomotor recovery in adult spinal CD1, BALB/c, and $\mathrm{C} 57 \mathrm{BL} / 6$ mice without training or pharmacological facilitation. Although we have observed spontaneous recovery in neonatally (P5) transected mice, we have not observed spontaneous recovery in Swiss-Webster mice transected at P35 or later, a result that parallels observations in spinal rats (Commissiong and Sauve, 1993; Molinari and Petrosini, 1993).

\section{The robotic system significantly enhanced training} effectiveness and enabled quantitative locomotion analysis The results of the present study demonstrate the significant value that robotic systems can bring to locomotor training and evaluation. In an active training mode, the mouse stepper significantly improved stepping ability in spinal mice within 1 week of training. In a passive recording mode, the mouse stepper elucidated subtle differences in stepping ability, distinguishing the effects of robotic training and quipazine treatment. By providing precise and consistent training, and enabling rapid quantitative recording and analysis of stepping data, robotic systems can greatly improve rehabilitation after an SCI.

\section{Summary}

The combination of robotic training and pharmacological treatment used in the present study illustrates how a multimodal strategy can be used to reinstate functional locomotion in mice after a complete spinal cord transection. Clearly, the neurotransmitter environment of the postinjury spinal cord is critically important in defining the functionality of the spinal circuitry and the extent to which it can be modified by specific sensory cues. The present results illustrate the feasibility of using robotic systems to train and to examine locomotor performance quantitatively in spinal mice and of extending these studies into relevant transgenic models. Future studies will examine the long-term effects of robotic training and/or quipazine treatment on functional recovery and will further quantify their interaction effect.

\section{References}

Anden NE, Haggendal J, Magnusson T, Rodengren E (1964) The time course of the disappearance of noradrenaline and 5-hydroxtryptamine in the spinal cord after transection. Acta Physiol 62:115-118.

Antri M, Orsal D, Barthe JY (2002) Locomotor recovery in the chronic spinal rat: effects of long-term treatment with a 5-HT2 agonist. Eur J Neurosci 16:467-476.

Barbeau H, Rossignol S (1990) The effects of serotonergic drugs on the locomotor pattern and on cutaneous reflexes of the adult chronic spinal cat. Brain Res 514:55-67.

Barbeau H, Rossignol S (1991) Initiation and modulation of the locomotor pattern in the adult chronic spinal cat by noradrenergic, serotonergic and dopaminergic drugs. Brain Res 546:250-260.

Behrman AL, Harkema SJ (2000) Locomotor training after human spinal cord injury: a series of case studies. Phys Ther 80:688-700.

Bosco G, Rankin A, Poppele RE (2003) Modulation of dorsal spinocerebellar responses to limb movement. I. Effect of serotonin. J Neurophysiol 90:3361-3371.

Bras H, Jankowska E, Noga B, Skoog B (1990) Comparison of effects of various types of NA and 5-HT agonists on transmission from group II muscle afferents in the cat. Eur J Neurosci 2:1029-1039.

Brustein E, Rossignol S (1999) Recovery of locomotion after ventral and ventrolateral spinal lesions in the cat. II. Effects of noradrenergic and serotoninergic drugs. J Neurophysiol 81:1513-1530.

Cazalets JR, Sqalli-Houssaini Y, Clarac F (1992) Activation of the central 
pattern generators for locomotion by serotonin and excitatory amino acids in neonatal rat. J Physiol (Lond) 455:187-204.

Chau C, Barbeau H, Rossignol S (1998) Early locomotor training with clonidine in spinal cats. J Neurophysiol 79:392-409.

Commissiong JW, Sauve Y (1993) Neurophysiological basis of functional recovery in the neonatal spinalized rat. Exp Brain Res 96:473-479.

de la Torre JC, Goldsmith HS (1990) Collagen-omental graft in experimental spinal cord transection. Acta Neurochir (Wien) 102:152-163.

de Leon RD, Hodgson JA, Roy RR, Edgerton VR (1998) Locomotor capacity attributable to step training versus spontaneous recovery after spinalization in adult cats. J Neurophysiol 79:1329-1340.

de Leon RD, Hodgson JA, Roy RR, Edgerton VR (1999a) Retention of hindlimb stepping ability in adult spinal cats after the cessation of step training. J Neurophysiol 81:85-94.

de Leon RD, Tamaki H, Hodgson JA, Roy RR, Edgerton VR (1999b) Hindlimb locomotor and postural training modulates glycinergic inhibition in the spinal cord of the adult spinal cat. J Neurophysiol 82:359-369.

de Leon RD, Reinkensmeyer DJ, Timoszyk WK, London NJ, Roy RR, Edgerton VR (2002) Use of robotics in assessing the adaptive capacity of the rat lumbar spinal cord. Prog Brain Res 137:141-149.

Dietz V (2001) Spinal cord lesion: effects of and perspectives for treatment. Neural Plast 8:83-90.

Dietz V, Colombo G (2004) Recovery from spinal cord injury—underlying mechanisms and efficacy of rehabilitation. Acta Neurochir Suppl 89:95-100.

Drugan RC, Grau JW, Maier SF, Madden JT, Barchas JD (1981) Cross tolerance between morphine and the long-term analgesic reaction to inescapable shock. Pharmacol Biochem Behav 14:677-682.

Dumoulin A, Privat A, Gimenez y Ribotta M (2000) Transplantation of embryonic Raphe cells regulates the modifications of the GABAergic phenotype occurring in the injured spinal cord. Neuroscience 95:173-182.

Dunteman GH (1989) Principal components analysis. Newbury Park: Sage Publications.

Edgerton VR, Roy RR, Hodgson JA, Gregor RJ, de Guzman CP (1991a) Recovery of full weight-supporting locomotion of the hindlimbs after complete thoracic spinalization of adult and neonatal cats. In: Restorative neurology, Vol 5, Plasticity of motoneuronal connections (Wernig A, ed), pp 405-418. New York: Elsevier.

Edgerton VR, de Guzman CP, Gregor RJ, Roy RR, Hodgson JA, Lovely RG (1991b) Trainability of the spinal cord to generate hindlimb stepping patterns in adult spinalized cats. In: Neurobiological basis of human locomotion (Shimamura M, Grillner S, Edgerton VR, eds), pp 411-423. Tokyo: Japan Scientific Societies.

Edgerton VR, de Leon RD, Tillakaratne NJ, Recktenwald MR, Hodgson JA, Roy RR (1997a) Use-dependent plasticity in spinal stepping and standing. In: Advances in neurology: neuronal regeneration, reorganization and repair (Seil FJ, ed), pp 233-247. Philadelphia: Lippincott-Raven.

Edgerton VR, de Leon RD, Tillakaratne NJ, Recktenwald MR, Hodgson JA, Roy RR (1997b) Use-dependent plasticity in spinal stepping and standing. Adv Neurol 72:233-247.

Edgerton VR, Roy RR, de Leon RD (2001) Neural Darwinism in the mammalian spinal cord. In: Spinal cord plasticity: alterations in reflex function (Patterson MM, Grau JW, eds), pp 185-206. Boston: Kluwer Academic.

Edgerton VR, Tillakaratne NJ., Bigbee AJ, de Leon RD, Roy RR (2004a) Locomotor recovery potential after spinal cord injury. In: Neurobehavioral determinants of interlimb coordination (Swinnen SP, Duysens J, eds), pp 53-91. Dordrecht, The Netherlands: Kluwer Academic.

Edgerton VR, Tillakaratne NJ, Bigbee AJ, de Leon RD, Roy RR (2004b) Plasticity of the spinal circuitry after injury. Annu Rev Neurosci 27:145-167.

Edgley SA, Jankowska E, Shefchyk S (1988) Evidence that mid-lumbar neurones in reflex pathways from group II afferents are involved in locomotion in the cat. J Physiol (Lond) 403:57-71.

Ellegala DB, Tassone JC, Avellino AM, Pekow CA, Cunningham ML, Kliot M (1996) Dorsal laminectomy in the adult mouse: a model for nervous system research. Lab Anim Sci 46:86-89.

Fedirchuk B, Dai Y (2004) Monoamines increase the excitability of spinal neurones in the neonatal rat by hyperpolarizing the threshold for action potential production. J Physiol (Lond) 557:355-361.

Feraboli-Lohnherr D, Orsal D, Yakovleff A, Gimenez y Ribotta M, Privat A (1997) Recovery of locomotor activity in the adult chronic spinal rat after sublesional transplantation of embryonic nervous cells: specific role of serotonergic neurons. Exp Brain Res 113:443-454.

Feraboli-Lohnherr D, Barthe JY, Orsal D (1999) Serotonin-induced activation of the network for locomotion in adult spinal rats. J Neurosci Res 55:87-98.

Fleetwood-Walker SM, Mitchell R, Hope PJ, Molony V, Iggo A (1985) An alpha 2 receptor mediates the selective inhibition by noradrenaline of nociceptive responses of identified dorsal horn neurones. Brain Res 334:243-254.

Giroux N, Reader TA, Rossignol S (2001) Comparison of the effect of intrathecal administration of clonidine and yohimbine on the locomotion of intact and spinal cats. J Neurophysiol 85:2516-2536.

Goldberger ME (1977) Locomotor recovery after unilateral hindlimb deafferentation in cats. Brain Res 123:59-74.

Gorassini M, Bennett DJ, Kiehn O, Eken T, Hultborn H (1999) Activation patterns of hindlimb motor units in the awake rat and their relation to motoneuron intrinsic properties. J Neurophysiol 82:709-717.

Grau JW, Barstow DG, Joynes RL (1998) Instrumental learning within the spinal cord. I. Behavioral properties. Behav Neurosci 112:1366-1386.

Grillner S, Wallen P, Hill R, Cangiano L, El Manira A (2001) Ion channels of importance for the locomotor pattern generation in the lamprey brainstem-spinal cord. J Physiol (Lond) 533:23-30.

Guertin PA (2004) Role of NMDA receptor activation in serotonin agonistinduced air-stepping in paraplegic mice. Spinal Cord 42:185-190.

Hains BC, Willis WD, Hulsebosch CE (2003) Serotonin receptors 5-HT1A and 5-HT3 reduce hyperexcitability of dorsal horn neurons after chronic spinal cord hemisection injury in rat. Exp Brain Res 149:174-186.

Harkema SJ (2001) Neural plasticity after human spinal cord injury: application of locomotor training to the rehabilitation of walking. The Neuroscientist 7:455-468.

Headley PM, Duggan AW, Griersmith BT (1978) Selective reduction by noradrenaline and 5-hydroxytryptamine of nociceptive responses of cat dorsal horn neurones. Brain Res 145:185-189.

Hill RH, Svensson E, Dewael Y, Grillner S (2003) 5-HT inhibits N-type but not L-type $\mathrm{Ca}^{2+}$ channels via 5-HT1A receptors in lamprey spinal neurons. Eur J Neurosci 18:2919-2924.

Hodgson JA, Roy RR, de Leon R, Dobkin B, Edgerton VR (1994) Can the mammalian lumbar spinal cord learn a motor task? Med Sci Sports Exerc 26:1491-1497.

Kazerooni H, Her M-G (1994) Dynamics and control of a haptic interface device. IEEE Trans Rob Autom 10:453-464.

Kiehn O, Johnson BR, Raastad M (1996) Plateau properties in mammalian spinal interneurons during transmitter-induced locomotor activity. Neuroscience 75:263-273.

Kim D, Adipudi V, Shibayama M, Giszter S, Tessler A, Murray M, Simansky KJ (1999) Direct agonists for serotonin receptors enhance locomotor function in rats that received neural transplants after neonatal spinal transection. J Neurosci 19:6213-6224.

Kim D, Murray M, Simansky KJ (2001) The serotonergic 5-HT(2C) agonist $m$-chlorophenylpiperazine increases weight-supported locomotion without development of tolerance in rats with spinal transections. Exp Neurol 169:496-500.

Laporte AM, Fattaccini CM, Lombard MC, Chauveau J, Hamon M (1995) Effects of dorsal rhizotomy and selective lesion of serotonergic and noradrenergic systems on 5-HT1A, 5-HT1B, and 5-HT3 receptors in the rat spinal cord. J Neural Trans 100:207-223.

Leblond H, L'Esperance M, Orsal D, Rossignol S (2003) Treadmill locomotion in the intact and spinal mouse. J Neurosci 23:11411-11419.

Liu ZY, Zhuang DB, Lunderberg T, Yu LC (2002) Involvement of 5-hydroxytryptamine(1A) receptors in the descending anti-nociceptive pathway from periaqueductal gray to the spinal dorsal horn in intact rats, rats with nerve injury and rats with inflammation. Neuroscience 112:399-407.

Lovely RG, Gregor RJ, Roy RR, Edgerton VR (1986) Effects of training on the recovery of full-weight-bearing stepping in the adult spinal cat. Exp Neurol 92:421-435.

Lovely RG, Gregor RJ, Roy RR, Edgerton VR (1990) Weight-bearing hindlimb stepping in treadmill-exercised adult spinal cats. Brain Res 514:206-218.

Machacek DW, Garraway SM, Shay BL, Hochman S (2001) Serotonin 5-HT(2) receptor activation induces a long-lasting amplification of spinal reflex actions in the rat. J Physiol (Lond) 537:201-207. 
Meuser T, Pietruck C, Gabriel A, Xie GX, Lim KJ, Pierce Palmer P (2002) 5 -HT7 receptors are involved in mediating 5-HT-induced activation of rat primary afferent neurons. Life Sci 71:2279-2289.

Miquel MC, Emerit MB, Nosjean A, Simon A, Rumajogee P, Brisorgueil MJ, Doucet E, Hamon M, Verge D (2002) Differential subcellular localization of the 5-HT3-As receptor subunit in the rat central nervous system. Eur J Neurosci 15:449-457.

Molinari M, Petrosini L (1993) Hemicerebellectomy and motor behaviour in rats. III. Kinematics of recovered spontaneous locomotion after lesions at different developmental stages. Behav Brain Res 54:43-55.

Moshonkina T, Avelev V, Gerasimenko Y, Mathur R, Bijlani RL (2002) Treadmill training accelerates restoration of locomotion after complete spinal cord transection in the rat. Indian J Physiol Pharmacol 46:499-503.

Ribotta MG, Provencher J, Feraboli-Lohnherr D, Rossignol S, Privat A, Orsal D (2000) Activation of locomotion in adult chronic spinal rats is achieved by transplantation of embryonic raphe cells reinnervating a precise lumbar level. J Neurosci 20:5144-5152.

Rossignol S, Bouyer L, Barthelemy D, Langlet C, Leblond H (2002) Recovery of locomotion in the cat following spinal cord lesions. Brain Res Brain Res Rev 40:257-266.

Roy RR, Hodgson JA, Lauretz SD, Pierotti DJ, Gayek RJ, Edgerton VR (1992)
Chronic spinal cord-injured cats: surgical procedures and management. Lab Anim Sci 42:335-343.

Roy RR, Talmadge RJ, Hodgson JA, Zhong H, Baldwin KM, Edgerton VR (1998) Training effects on soleus of cats spinal cord transected (T12-13) as adults. Muscle Nerve 21:63-71.

Shay BL, Hochman S (2002) Serotonin alters multi-segmental convergence patterns in spinal cord deep dorsal horn and intermediate laminae neurons in an in vitro young rat preparation. Pain 95:7-14.

Timoszyk WK, de Leon RD, London N, Joynes R, Minakata K, Roy RR, Edgerton VR, Reinkensmeyer DJ (2003) Comparison of virtual and physical treadmill environments for training stepping after spinal cord injury. Robotica 21:25-32.

Tukey JW, Cooley JW (1965) An algorithm for the machine calculation of complex Fourier series. Math Comput 19:297-301.

Wernig A, Nanassy A, Muller S (1999) Laufband (treadmill) therapy in incomplete paraplegia and tetraplegia. J Neurotrauma 16:719-726.

Wikstrom M, Hill R, Hellgren J, Grillner S (1995) The action of 5-HT on calcium-dependent potassium channels and on the spinal locomotor network in lamprey is mediated by 5-HT1A-like receptors. Brain Res 678:191-199. 